\title{
The Link between Salary and Psychiatric Problems among the Industrial Workers
}

\author{
Syed Khalid Perwez ${ }^{1}$, Abdul Khalique ${ }^{2}$, H. Ramaseshan ${ }^{1} \&$ T. N. V. R. Swamy ${ }^{1}$ \\ ${ }^{1}$ VIT Business School, VIT University, Vellore, Tamil Nadu, India \\ ${ }^{2}$ P.G Department of Psychology, Ranchi University, Ranchi, India \\ Correspondence: Syed Khalid Perwez, VIT Business School, VIT University, Vellore-632014, Tamil Nadu, India. \\ E-mail: khalid_mba@rediffmail.com; abdulkhalique25@yahoo.com
}

\author{
Received: July 26, 2013 Accepted: February 4, 2014 Online Published: March 31, 2014 \\ doi:10.5539/ass.v10n7p87 \\ URL: http://dx.doi.org/10.5539/ass.v10n7p87
}

\begin{abstract}
The current study aimed to examine the effect of salary (High and low) on psychiatric problems of 200 workers of Tata Motors Ltd, Jamshedpur. These workers were divided on the basis of salary (high / low paid) and nature of job (high / low risk). Thus, there were four sub-groups and in each sub-group there were 50 cases. Methods: The Middlesex Hospital Questionnaire (M.H.Q) constructed by Crown \& Crisp, (1966) and adapted in Hindi by O.N. Srivastava and V.K. Bhat in 1974 was administered on these 200 workers. Results: Results clearly indicated that salary (high and low) played a significant role in creating psychiatric problems in workers. Workers doing low paid jobs showed more psychiatric problems compared to workers doing high paid jobs in both high risk and low risk categories. The symptoms like free-floating anxiety, obsession traits and symptoms, phobic anxiety, somatic concomitants of anxiety, neurotic depression, and hysterical personality traits were found stronger in low paid in comparison to high paid industrial workers. Conclusion: Low paid job workers had significantly more psychiatric problems compared to high paid job workers.
\end{abstract}

Keywords: psychiatric problems, nature of jobs, industrial workers

\section{Introduction}

Behaviour under stress is one of the major concerns of the behavior scientists at the present time. People's life is becoming more and more stressful today resulting in to a serious cost for society, both in human and monetary terms. Though stress at work has become a prominent and pervading feature of modern organizations, the individual as well as the organization cannot remain in a state of continuous stress. They certainly adopt one or the other strategy to deal with the perceived stress, which in turn put differential effects on their job behaviour and overall physical and mental health.

Especially in automobile and steel industry this can be seen very clearly because of their sensitive nature of duty (shift duty) and insecure work place. In fact, they develop mental health problem very fast. And it is well known that mental ill-health impairs one's ability to work effectively. For these reasons, it is important to understand the exact nature of stress responses, so that we can devise ways and means to protect the modern man from the clutches of the devil he himself has created and a stable and harmonious equilibrium between man and his environment can be maintained which ultimately lead a more productive and satisfying life.

The burden of mental disorders on health and productivity throughout the world has long been profoundly underestimated (US Surgeon General, 2000). The impact of mental health problems in the work place has serious consequences not only for the individuals whose lives are influenced either directly or indirectly, but also for enterprise productivity. Mental health problems strongly influence the employee's performances, rates of illness, absenteeism, accidents and staff turnovers.

WHO defines health as: "Health is a state of complete, physical, mental and social well being and not merely absence of disease or infirmity." (WHO, 1978).

Mental health deals with psychology of normal working people, not with psychiatric causes, but it focuses on an overall assessment of the mental health of these men. The concept of mental health is taken in a wider sense. It is not a representation of any psychodynamic unit but as a loose description, designated for an overall level of success, personal satisfaction, effectiveness and excellence of the individual's functioning at present. 
Mental health means the ability to balance feelings, desires, ambitions, and ideals in our daily life. It means the ability to face and accept the realities of life (Kuppuswami, 1962).

In the organization of industrial life, a man will not be happy unless he is able to do his job satisfactorily and with satisfaction. This sense of achievement and this sense of quality are fundamental to man's happiness and are inherent in Aristotle's concept of the good life or happiness as "Living well and doing well".

Some people at their jobs in the factory look, feel and behave differently. They will often appear bored, irritated, frustrated and tense, probably grumbling about the management and perhaps watching the clock until they can leave. Some will be political extremists, others just the rather unhappy people, who are to be found in every industrial community. In the factory escape into strikes, absenteeism, illness and psychosomatic breakdown is unduly common, and these factors play an important role in the industrial mental health and also affect the productivity in all industrialized countries. Moreover, these minor psychological symptoms usually remain unnoticed and so do not receive professional assistance. The practical importance of these symptoms lies in the fact that not only they lead to impairment in productivity, but also mistakes at work and accident proneness (August, 1977).

Besides, there may be deterioration leading to syndrome psychiatric disorders. Kar et al., (2002) observed that anxiety symptoms like inner tension, worrying, concentration difficulty, indecision and depressive symptoms like sad mood, fatigability, pessimistic thought, and inability to feel were reported by more than $5 \%$ of industrial employees. Somatic symptoms like reduced sleep, decreased appetite, reduced sexual drive, aches and pains, muscular tension and hostile feeling were also very common.

From all these observations, what we want to reflect is that stress is a part and parcel of the industrial life process. But, we use the term stress only to connate overloading of the psycho-physiological system by a trigger of some such conditions external or internal that is being perceived by the individual as threatening to his existence and giving rise to some kind of maladaptive behavior.

\section{Literature Review}

Psychiatric disorder associated with anxiety, depression, sleep disturbance and related symptoms have been reported to be prevalent in the community and the work place.

The pioneer scientific study in relation to mental health and distress of individual workers was conducted by Kornhauser (1964). He found that a worker's performance at his task is closely related to his mental health. Since then many attempts have been made in this regard (Agrawal \& Divakar, 2003; Beehr \& Newman, 1987; Kar et al., 2003; Mittal et al., 2000; Mohanty et al., 1998; Samanta \& Singh, 1993; Srivatava, 1991) He studied the psychological condition of workers in modern mass production industries and attempted to assess and compare the mental health of men at higher and lower skill levels, with special attention to the human effects of a routine production job.

Dewa, Lin, Kooehoorn and Goldner (2007) studied the links between psychiatric disorders and work-related stress as well as between psychiatric disorders and physical conditions. The study explores the relationships between chronic work stress, psychiatric disorders, and chronic physical conditions and disability among workers.

The psychiatric symptoms could be the result of the increased stress levels at work as reported by Sauter et al (1990). Dysfunctional interpersonal relationship (Cooper, 1983), increased job pressure, greater responsibility without authority and feeling of insecurity (Sadok, 1995) have been reported as the sources of stress. Career problem and pressure for production are also known to increase stress (Karasek et al., 1992).

Janyam k. (2011) investigated factory worker's mental health to examine the level of job satisfaction and to identify the dimension of job that influences the mental health. The results revealed that $33.5 \%$ of the workers had poor mental health with anxiety and insomnia at highest level followed by somatic symptoms and depression. He found that pay and work security is one of the most important factors for job satisfaction and mental health.

Kar et al (2002) observed that anxiety symptoms like inner tension, worrying, concentration difficulty, indecision, and depressive symptoms like sad mood, fatigability, pessimistic thought and inability to feel were reported by more than $5 \%$ of industrial employees. Somatic symptoms like reduced sleep, decreased appetite, reduced sexual drive, aches and pains, muscular tension were also very common. A considerable proportion had hostile feelings.

Khalique and Khalid (2009) studied the effect of occupational stress and general well-being. The study is conducted on sales \& marketing professionals working in various top most companies. They found that role 
ambiguity, role conflict, unreasonable group pressures, impoverishment, low status, strenuous working conditions, unreliability and responsibility of persons are the factors which contribute more occupational stress which is turn affects the General well-being of the individual. The researchers concluded that higher the occupational stress lower is the General well-being.

In another study Khalid and Khalique (2012) examined the effect of nature of job (High risk / low risk) on occupational stress of 200 workers of Tata Motors Ltd, in Jamshedpur. Results clearly indicated that nature of job (high and low risk) played a significant role in creating stress in workers. Workers doing high risk jobs showed greater stress compared to workers doing low risk jobs in both high paid and low paid categories.

It is evident from the review of literature that there is a great dearth of systematic socio-psychological studies on the relationship of the salary of industrial workers with their psychiatric problems particularly in Indian condition. The present study tries to bridge this gap with the following objectives:

1) To study the effect of income (high and low paid job workers) on psychiatric problems.

2) To examine the probability of psychiatric problems of industrial workers.

3) To find out the important symptoms that cause psychiatric problems among the low and high paid industrial workers.

\section{Hypothesis}

In pursuance of the above mentioned objectives, the following hypothesis had been formulated:

Low paid workers show more psychiatric problems than high paid workers.

\section{Methodology}

\subsection{Sample}

A sample of 200 workers was selected from the TATA Motors Ltd., Jamshedpur. The workers were divided into two categories namely 'High Paid' and 'Low Paid' workers and further these workers were sub-divided into two categories, that is, 'High Risk' and 'Low Risk job' workers. The sample was based on a 2x2 factorial design. Therefore, there were four sample sub-groups and each sub-group was represented by 50 workers, making a total of 200 .

\subsection{Tools}

The following tools have been used in the present study for the collection of data:

\subsubsection{Personal Data Sheet}

Personal Data Sheet was specially designed for the present study which include data related to personal identification of the workers, specially their names, addresses, factories in which they are working, designation, nature of the job and salary etc.

\subsubsection{The Middlesex Hospital Questionnaires (M.H.Q.)}

The presence of mental ill health of the Tata Motors Workers was measured by using the Hindi version of the Middlesex Hospital Questionnaire. The Middlesex Hospital Questionnaire is a self rating scale. It is a short and simple scale which takes hardly 7-10 minutes for administration. It is constructed by Crown \& Crisp (1966) and adapted in Hindi by O.N. Srivastava and V.K. Bhat in 1974. This test provides a rapid quantification of common symptoms and traits relevant to the conventional diagnostic categories of neurotic illness. This test consists of six sub-scales having 08 questions in each. These sub scales are: Free-floating anxiety (FFA), Obsessional traits and symptoms (OBS), Phobic anxiety (PHO), Somatic concomitants of anxiety (SOM), Neurotic depression (DEP) and Hysterical personality traits (HYS).

Since the number of items in each sub-scale is 08 , so the total number of items in the test is 48 . And all the sub scales have a uniform structure and scoring system. The 08 items of each sub-scale have been put into 2 clusters of 4 items each. The first cluster of 4 items from each of the sub-scales follows in a sequence and then the second cluster of each of the sub-scales follows in the next sequence. The first half of the whole test thus contains the first halves of all the sub-scales. The order in which the clusters of items appear is: FFA, OBS, PHO, SOM, DEP and HYS respectively.

The split half reliability of the whole test (i.e. between the first 24 items vs. the next 24 items) is . 70 . For the 6 sub-scales the reliability co-efficient are $.88, .76, .52, .68, .74$ and .66 respectively. The validity co-efficient is quite high and well established. 


\section{Statistical Analyses}

The following statistical techniques have been used in the analysis of obtained data:

1) As the data is based on a $2 \times 2$ factorial design the analysis of variance (ANOVA) have been used to examine the effect of factors.

2) The sub-groups based on the nature of jobs have been compared by t-test.

3) The mean scores have also been calculated and graphically shown.

\section{Results and Discussion}

One of the objectives of the present research is to examine the relationship of level of payment (high and low paid) with psychiatric problems. In other word, which is more sensitive to psychiatric problems, high paid worker or low paid job workers? To get the answer of this question the analysis of data has been done. The analysis of variance, mean scores and t-tests have also been computed to examine the significance level of mean difference. The results have also been presented in different tables and graph.

The main effect of income/salary (high paid and low paid) on psychiatric problems is being reported here. F-ratio determining the role of the level of payment for the total M.H.Q. and its sub-scales has been given in Table 1.

Table 1. Analysis of variance of scores on Middlesex hospital questionnaire (MHQ) and its sub-scales: level of payment

\begin{tabular}{|c|c|c|c|c|c|}
\hline \multicolumn{2}{|c|}{ SOURCE OF VARIATION PAYMENT } & \multirow{2}{*}{ SUM OF SQUARES } & \multirow{2}{*}{$\mathrm{df}$} & \multirow{2}{*}{ Mean square } & \multirow{2}{*}{ F - ratio } \\
\hline 6 & SUB SCALES OF M.H.Q. & & & & \\
\hline I. & Free Floating Anxiety (FFA) & 36.125 & 1 & 36.125 & $6.110 * *$ \\
\hline II. & Obsession Compulsion (OBS) & 13.005 & 1 & 13.005 & 2.426 \\
\hline III. & Phobia (PHO) & 4.500 & 1 & 4.500 & .944 \\
\hline IV. & Somatic Complaints (SOM) & 12.500 & 1 & 12.500 & 1.656 \\
\hline $\mathrm{V}$. & Depression (DEP) & 23.120 & 1 & 23.120 & $3.627^{*}$ \\
\hline \multirow[t]{2}{*}{ VI. } & Hysteria (HYS) & 12.500 & 1 & 12.500 & 2.654 \\
\hline & TOTAL M.H.Q. & 557.780 & 1 & 557.780 & $3.091 *$ \\
\hline
\end{tabular}

$* *=$ Significant at above .01 level $/ *=$ Significant at .05 level

The above table reveals that out of 07 F-ratios, only 03 are significant, one at 0.01 level and two at .05 levels. Other 04 F-ratios are not significant. The F-ratio for Free Floating Anxiety (FFA) is significant at .01 level whereas F-ratios for Depression (DEP) and Total MHQ are significant at .05 level. In the light of this finding it may be concluded that level of payment (high/low paid) significantly influence FFA, DEP and MHQ whereas in other areas of psychiatric problem like obsession compulsion (OBS), Phobia (PHO), Somatic Complaints (SOM) and Hysteria (HYS) it has no role.

The mean scores of high paid and low paid job workers have been given in Table 2 which reveals that in the areas of psychiatric problems like FFA, DEP and total of MHQ where significant F-ratios have been found the low paid workers have obtained significantly higher mean scores as compared to high paid workers. Thus, it may be safely concluded that low paid workers have high free floating anxiety, depression and overall psychiatric problems as compared to high paid workers. 
Table 2. Mean scores of high paid \& low paid job workers on MHQ and its sub-scales

\begin{tabular}{llcc}
\hline & & HIGH PAID & LOW PAID \\
\cline { 3 - 4 } & & $\mathrm{N}=100$ & $\mathrm{~N}=100$ \\
\hline 6 & SUB SCALES OF M.H.Q. & MEAN & MEAN \\
I. & Free Floating Anxiety (FFA) & 6.82 & 7.67 \\
II. & Obsession Compulsion (OBS) & 5.14 & 5.65 \\
III. & Phobia (PHO) & 4.33 & 4.63 \\
IV. & Somatic Complaints (SOM) & 6.13 & 6.63 \\
V. & Depression (DEP) & 5.46 & 6.14 \\
VI. & Hysteria (HYS) & 4.72 & 5.22 \\
& TOTAL M.H.Q. & 32.63 & 35.94 \\
\hline
\end{tabular}

The table discussed has also been graphically depicted in Figure 1. It can be seen in the graph that the bars of low paid job workers are bigger in FFA, DEP and M.H.Q. than those of high paid job workers. In other areas of psychiatric problems like OBS, PHO, SOM and HYS there is not much variation in the size of the bars.

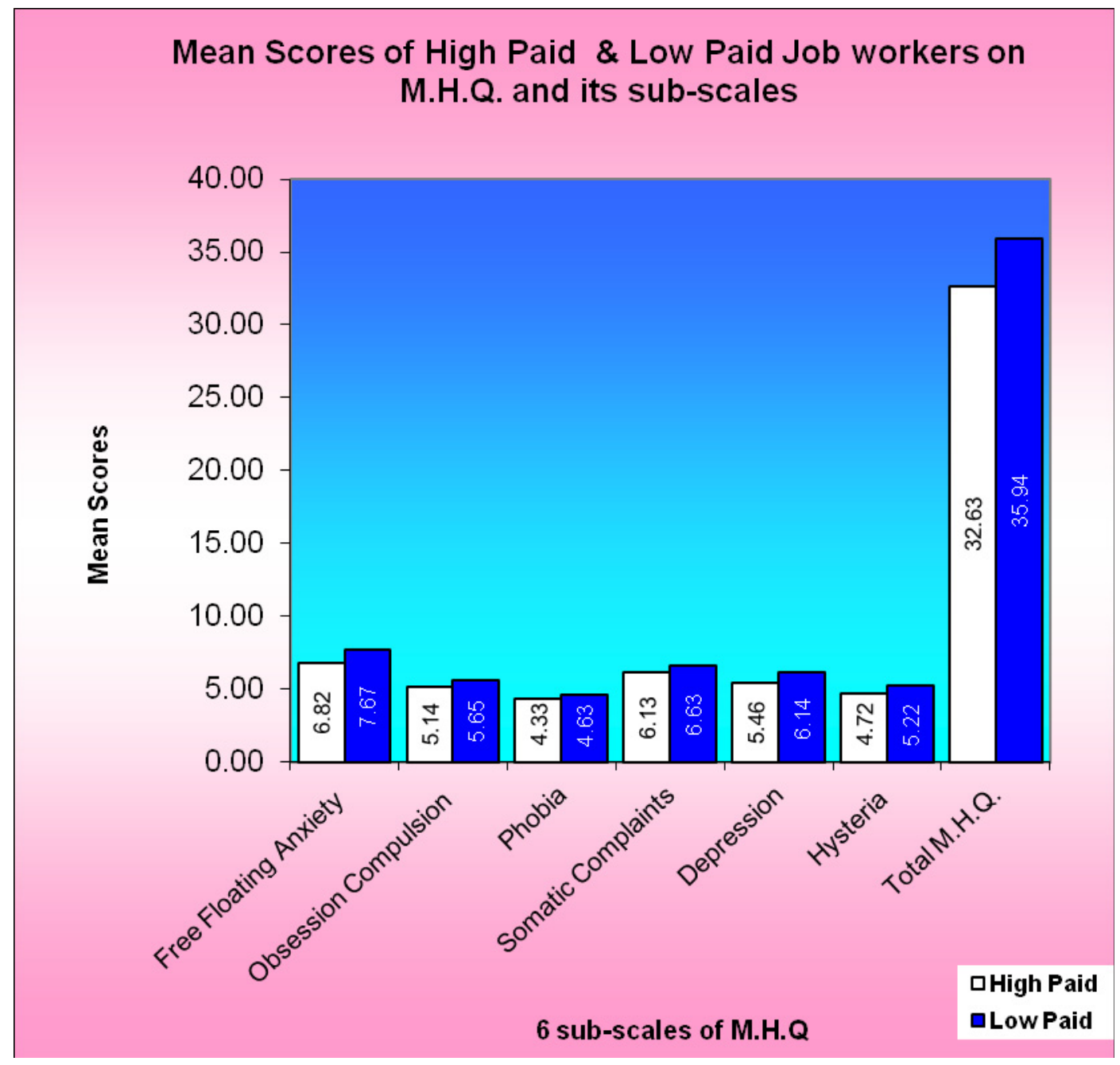

Figure 1.

Considering the trend of significance of F-ratios the high paid and low paid sub-groups have been compared through t-tests separately for high risk and low risk job workers on M.H.Q. and its sub-scales. Table 3 presents 
the t-values comparing the high paid and low paid job workers doing high risk jobs. The following main tendencies may be noted in this table:

1) Out of 07 comparisons, t-values are significant only in 02 comparisons, that is, in the areas of Free Floating Anxiety (FFA) and Obsession Compulsion (OBS) and in both the sub-scales of MHQ the low paid workers have significantly higher mean scores compared to high paid workers.

2) In other areas of psychiatric problem like PHO, SOM, DEP, HYS and in total MHQ where even if no significant $t$-values have been found the same tendencies of mean scores are noted. The low paid workers have slightly higher mean scores in these sub-scales of MHQ than the high paid workers. Therefore, it is observed that low paid workers as compared to high paid workers have more psychiatric problems.

Table 3. Comparisons of high paid and low paid job workers of high risk job category on M.H.Q. and its sub-scales: t-values

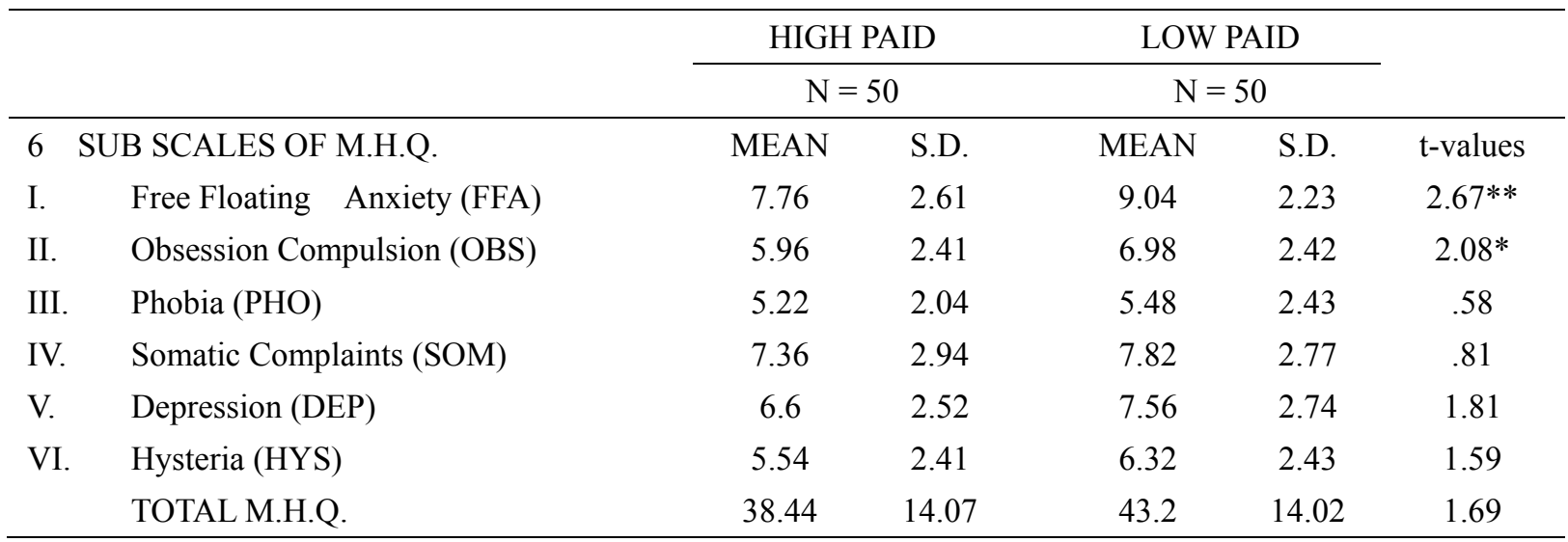

$* *=$ Significant at above .01 level $/ *=$ Significant at above .05 level

Table 4 presents the comparisons of high paid and low paid job workers on M.H.Q. and its sub-scales doing low risk jobs. It may be seen in this table that none of the $t$-values are statistically significant. But the trend of mean scores, like the workers doing high risk jobs, reveals that low paid workers have obtained higher mean scores in all the sub-scales of MHQ as well as in Total MHQ except in one sub-scale of obsession compulsion (OBS) where the mean score of both the high and low paid workers is the same. Thus, the result partially supports that low paid workers have high psychiatric problem in comparison to high paid workers.

Table 4. Comparisons of high paid and low paid job workers of low risk job category on M.H.Q. and its sub-scales: $\mathrm{t}$ - values

\begin{tabular}{llccccc}
\hline & & \multicolumn{2}{c}{ HIGH PAID } & \multicolumn{2}{c}{ LOW PAID } & \\
\cline { 3 - 6 } & & \multicolumn{2}{c}{$\mathrm{N}=50$} & \multicolumn{2}{c}{$\mathrm{N}=50$} \\
\hline 6 & SUB SCALES OF M.H.Q. & MEAN & S.D. & MEAN & S.D. & t-VALUES \\
I. & Free Floating Anxiety (FFA) & 5.88 & 2.47 & 6.3 & 2.39 & .88 \\
II. & Obsession Compulsion (OBS) & 4.32 & 2.35 & 4.32 & 2.06 & 0 \\
III. & Phobia (PHO) & 3.44 & 2.17 & 3.78 & 2.07 & .81 \\
IV. & Somatic Complaints (SOM) & 4.9 & 2.67 & 5.44 & 2.60 & 1.02 \\
V. & Depression (DEP) & 4.32 & 2.34 & 4.72 & 2.48 & .83 \\
VI. & Hysteria (HYS) & 3.9 & 1.94 & 4.12 & 1.84 & .56 \\
& TOTAL M.H.Q. & 26.82 & 13.06 & 28.68 & 12.66 & .72 \\
\hline
\end{tabular}

\section{Conclusions}

To examine the role of income/salary (high/low paid) on psychiatric problems it has been hypothesized that: 


\section{"low paid workers show more psychiatric problems than high paid workers".}

In the light of analyses and discussions made above, it has been observed that the role of the level of payment (high paid and low paid) on M.H.Q. and its sub-scales is not very clearly determined by F-ratios (Table 1). Out of 7 F-ratios only 3 F-ratios are statistically significant at .05 levels. In the all the comparisons the mean scores of low paid job workers are higher than high paid job workers (Table 2 and Figure 1).

Further the comparisons made through t-tests (Tables 3 and 4) have confirmed the trend obtained from F ratios. In other words, the data partially support the hypothesis that low paid job workers have more psychiatric problems than high paid workers. In the light of these analyses and discussions the above said hypothesis has been partially supported as the low paid job workers have obtained significantly higher mean scores only in some of the scales of M.H.Q. compared to those obtained by high paid job workers.

It is common knowledge that much time is lost in factories because of neurotic symptoms. Doubts, as to social security, boredom from the monotony of mechanized jobs, fear of employment or of inability to work, all have a decidedly injurious psychological effect on the workman. In spite of the various efforts made to interest him in his task, including social work of all kinds, incentives schemes sharing in benefits, paid holidays and national insurance, the fact remains that large numbers of industrial workers have lost joy in their work. In a world, which is so insecure, it is not surprising that anxiety and depression arising from feeling of instability should plunge into psychoneurosis in those people who are so predisposed. Factors tending to produce neurosis are uncongenial working condition, mental sub normality, poor placement in which the job requires more skill than the operative processes, together with extra-factory stresses related to the worker's social and domestic life.

Early workers felt that environmental stresses produced a specific unconscious conflict in the patient, which then led to anxiety and depression and to the arousal of a specific psychodynamic pattern involving regression, which in turn led to a specific regressive physiological concomitant, and finally to a specific psycho physiological symptoms or disease.

\section{References}

Agarawal, K. (1998). Job satisfaction and occupational stress in relation to felt proximity with top management. Indian Journal of Psychometry and Education, 29(5), 113-114.

Agarwal, S. M., \& Divakara, P. G. (2003). Psychiatric Morbidity in a Steel Industry. Industrial Psychiatry Journal, 12(1), 58-62.

Ahmad, S., \& Ahmad, H. (1992). Role Stress and Work Satisfaction: A Study on Middle Managers. Industrial Psychiatry Journal, 5(1), 15-21.

Ahmad, S., \& Razzack, B. (1983). A Study of Mental Health and Job Satisfaction of Industrial Workers. Indian Journal of Clinical Psychology, (10), 239-244.

Bhatia, S. (1999). Stress management in the work place. Praachi Journal of Psycho-Cultural Dimensions, 15(2), 111-114.

Biswas, U. N. (1998). Life-style stressors, organizational commitment, job involvement, and perceived organizational effectiveness across job levels. Indian Journal of Industrial Relations, 34(1), 55-72.

Chandraiah, K., Kenswar, D. K., Prasad, P. L. S., \& Chaudhuri, R. N. (1996). Occupational stress and job satisfaction among middle and senior managers. Indian Journal of Clinical Psychology, 23(2), 146-155.

Chandrasekhar, S. F., Chandra Mouli, D., \& Anjaiah, P. (1995). Job stress and psycho-somatic problems of nurses at select hospitals. Indian Journal of Applied Psychology, 32(1-2), 1-5.

Cohen, S., \& Williamson, G. M. (1991). Stress and infectious disease in humans. Psychological Bulletin, 109, 5-24. http://dx.doi.org/10.1037/0033-2909.109.1.5

Costa, G. (1993). The Impact of Shift and Night Work on Health (International Congress on Occupation Health). Applied Ergonomics, 27(1), 9-16. http://dx.doi.org/10.1016/0003-6870(95)00047-X

Deousa, A., \& Deousa, D. A. (1990). Stress in Industry. Industrial Psychiatry Journal, 3(1), 37-38.

Deousa, A., Deousa, D. A., Sinorwala, A. K., \& Boxwwalla, S. (1999). Stress and Coping in Industrial Workers. Industrial Psychiatry Journal, 3(1), 70-71.

Doby, V. J., \& Caplan, R. D. (1995). Organizational Stress as threat to reputation: Effects on Anxiety at Work and at Home. Academy of Management Journal, 38(4), 1105-1123. http://dx.doi.org/10.2307/256622

Eliashof, B. A., \& Streltzer, J. (1992). The Role of 'Stress' in Workers Compensation Stress Claims. Journal of 
Occupational Medicine, 34(3), 297-302. http://dx.doi.org/10.1097/00043764-199203000-00015

Ferguson, D. (1973). A Study of Occupational Stress and Health. Ergonomics, 16(5), 649-663. http://dx.doi.org/10.1080/00140137308924555

Filoswsky, I. (1973). Psychiatric Aspects of Stress. Ergonomics, 16(5), 691-698. http://dx.doi.org/10.1080/00140137308924560

Janyam, K. (2011). The influence of job satisfaction on mental health of factory workers. The international Journal of Mental Health, 7(1).

Jena, S. P. K. (1999). Job satisfaction, and occupational stress of women. Social Science International, 15(1), 75-80.

Kar, N., \& Haridas, K. (2003). Mental III health in Industrial Environment: Risk Factors and Management Issues. Industrial Psychiatry Journal, 12(1), 3-6.

Khalid, \& Khalique. (2012). Nature of job and occupational stress: A study of workers of an industry. International Journal of Physical Social Sciences, 2(2).

Khalique, \& Khalid. (2009). A study on occupational stress and general well being in sales professionals. Behavioural Research Review, 1(1), 56-59.

Kirkcaldy, B., Cooper, C. L., \& Ruffalo, P. (1995). Work Stress and Health in a sample of U.S. Police. Psychological Reports, 76(2), 700-702. http://dx.doi.org/10.2466/pr0.1995.76.2.700

Kohler, G. (1992). Combating Office Stress with the Martial Arts. Occupational Hazards, 10, 123-126.

Lazarus, R. S. (1966). Psychological Stress and the Coping Process. New York: McGraw-Hill.

Mehra, G., \& Mishra, P. C. (1991). Mental Health as a Moderator variable of Intrinsic Job Satisfaction and Occupational Stress. Psychological Studies, 36(3), 198-202.

Misra, G., \& Jain, U. G. (1996-97). Stress vulnerability: Nature and determinants. Perspectives in Psychological Researches, 19-20(1-2), 42 -54.

Morris, J. K., \& Cook, D. G. (1991). A critical review of the effect of Factory Closure on Health. British Journal of Industrial Medicine, 48(1), 1-8.

Nanda, P. K., Dass, P. K., \& Mishra, D. C. (1989). Hazards of Work Environment and Mental Health. Industrial Psychiatry Journal, 2(1), 39-41.

Nilson et al. (1992). Mental and Psychosomatic Work Injuries in Sweden. Journal of Occupational Medicine, 34(7), 726-730.

Pattanayak, B. P., \& Dhar, U. (1998) Psychological correlates of hierarchy and work area-A study in the Rourkela Steel Plant. Management and Labour Studies, 23(1), 269-276.

Rao, K. (1990). Stress and Illness: An Overview. Indian Journal of Psychiatry, 13-23.

Sasi, P. T., Srivastava, A., \& Sharma, R. G. (1990) the Relationship between Stress, Social Support and Psychiatric Symptomatology among Industrial Workers. Indian Journal of Psychiatry, 3(7), 26-29.

Sharma, M., \& Kumari, K. B. (1998). An empirical study of stress and performance appraisal. Praachi Journal of Psycho-Cultural Dimensions, 14(1), 29-32.

Sharma, S., \& Acharya, T. (1989). Coping Strategies and Anger Expression. Journal of Personality and Clinical Studies, 5(1), 15-18.

Sharma, S., \& Sharma, U. (1983). Relationship of Organizational role Efficacy with Anxiety and Job Satisfaction at Two Job Levels. Indian Journal of Clinical Psychology, 10, 319-323.

Shukla, T. R., \& Kumar, S. (1989). A Study of Psychoneurosis in Industries. Industrial Psychiatry Journal, 2(1), 27-29.

Singh, K. (1989). A Study of Mental Illhealth in E.S.I. Population in Delhi. Industrial Psychiatry Journal, 2(1), 31-37.

Singh, S. (1990). Organizational Stress and Executive Behaviours New Delhi. Shri Ram Centre for Industrial Relations.

Somanta, C. R., \& Singh, A. (1993). Distress and Job Performance of Industrial Workers. Indian Journal of Psychiatry, 35(2), 119-121. 
Srivastava, A. K. (1991). A Study of Role Stress Mental Health Relationship as Moderated by Adopted Coping Strategies. Psychological Studies, 36(3), 192-197.

Srivastava, A. K., \& Singh, A. P. (1981). Mannual of the Occupational Stress Index Varanasi: Department of Psychology, Banaras Hindu University.

Srivastava, O. N., \& Bhat, V. K. (1974). The Middle - Sex Hospital Questionnaire (M.H.Q.) Standardization on a Hindi Version. Indian Journal of Psychiatry, 16, 283-286.

Steptoe, A. (1991). The Link between Stress and Illness. Journal of Psychosomatic Research, 35, 633-644. http://dx.doi.org/10.1016/0022-3999(91)90113-3

Studenski, R., \& Barezxyk, J. (1989). Frequency of Exposure to Occupational Stressors, Job Satisfaction and Morbid States. Polish-Psychological Bulletin, 20(3), 183-187.

Taylor, P., \& Gardner, W. (1975). Health at Work. New York: A division of John willey and sons Inc.

Taylor, S. (1991). Health Psychology. New York: Random House.

Tharakan, P. N. O. (1991). Organizational Stress and Executive Behaviour. Psychological Studies, 36(3), 219-220.

\section{Copyrights}

Copyright for this article is retained by the author(s), with first publication rights granted to the journal.

This is an open-access article distributed under the terms and conditions of the Creative Commons Attribution license (http://creativecommons.org/licenses/by/3.0/). 